\title{
Comparison Postoperative Shoulder Pain, Nausea, and Vomiting Between Low and Normal Pressure Pneumoperitoneum in
}

\section{Laparoscopic Cholecystectomy}

\author{
Behzad Nematihonar, ${ }^{1}$ Hosein Fahimihanzaei, ${ }^{2}$ Mohammadreza Kamranmanesh,, ${ }^{3}$ Elham Memary, \\ Arash Shahbazi, ${ }^{4}$ and Alireza Mirkheshti ${ }^{5,}$ \\ ${ }^{1}$ Assistant Professor of Surgery, Shahid Beheshti University of Medical Sciences, Tehran, Iran \\ ${ }^{2}$ Fellowship of Thoracic and Laparoscopic Surgery \\ ${ }^{3}$ Assistant Professor of Anesthesiology, Shahid Beheshti University of Medical Sciences, Tehran, Iran \\ ${ }^{4}$ Resident of Surgery, Shahid Beheshti University of Medical Sciences, Tehran, Iran \\ ${ }^{5}$ Associate Professor of Anesthesiology, Shahid Beheshti University of Medical Sciences, Tehran, Iran \\ "Corresponding author: Alireza Mirkheshti, MD, Associate Professor of Anesthesiology, Shahid Beheshti University of Medical Sciences, Imam Hossein Medical Centre, Madani \\ St, Tehran, Iran. Tel/Fax: +98-2177567840, E-mail: drmirkheshti@gmail.com
}

Received 2017 March 27; Revised 2017 April 30; Accepted 2017 May 27.

\begin{abstract}
Background: Low-pressure pneumoperitoneum during laparoscopic surgeries decreases some side effects related to inflate gas into abdominal cavity. The current study aimed at comparing the effects of standard- and low-pressure pneumoperitoneum on shoulder pain, nausea, and vomiting after laparoscopic cholecystectomy.

Methods: In a randomized clinical trial, 202 ASA classes I and II patients, candidates for elective laparoscopic cholecystectomy, were randomly divided into the groups of standard-(12 to $14 \mathrm{mmHg}$ ) and low-(6 to $7 \mathrm{mmHg}$ ) pressure pneumoperitoneum. Postoperative shoulder pain, nausea, and vomiting were assessed between the 2 groups.

Results: Post-operative shoulder pain was statistically lower in low-pressure group in comparison with standard-pressure group (P $=0.001)$. Nausea and vomiting were not statistically different between the 2 groups $(P=0.54)$.

Conclusions: Low-pressure pneumoperitoneum during laparoscopic cholecystectomy was an efficient method to decrease postoperative shoulder pain.
\end{abstract}

Keywords: Pneumoperitoneum, Cholecystectomy, Laparoscopic

\section{Background}

Since the last decade laparoscopic cholecystectomy is the gold standard for cholecystectomy, which result in fewer complications and less hospital stay than open surgeries $(1,2)$. Laparoscopic cholecystectomy can be performed using low-pressure in approximately $90 \%$ of people (3). In some studies, it is shown that low-pressure pneumoperitoneum (less than $10 \mathrm{mmHg}$ ) is a feasible and safe technique and results in decreased postoperative pain and nearly the same operative time compared with standardpressure pneumoperitoneum (12 to $16 \mathrm{mmHg}$ )(4). As there are some different conclusions about the benefits of lowpressure pneumoperitoneum than the standard-pressure in laparoscopic cholecystectomy surgeries, it was intended to compare postoperative shoulder pain, nausea, and vomiting in these 2 techniques.

\section{Methods}

After getting approval by research ethics committee of Shahid Beheshti University of Medical Sciences and written consent from all participants, through a double blinded clinical trial, 202 ASA classes I and II patients within the age range of 15 to 85 years, candidates for elective laparoscopic cholecystectomy, were randomly divided into 2 groups of low-pressure ( 6 to $8 \mathrm{mmHg}$ ) and standard-pressure pneumoperitoneum (12 to $16 \mathrm{mmHg}$ ). All cases with pregnancy, purulent cholangitis, carcinomas, previous laparotomy, and history of addiction or psychologic disorders were excluded from the study. If laparoscopic procedures changed to open cholecystectomy or intraoperative bleeding was more than $500 \mathrm{~mL}$, or if the operation took more than 2 hours the case was excluded from the study. All patients were monitored by electrocardiography(ECG), blood pressure and cerebral state index, $\mathrm{SpO} 2$ (normal blood oxygen saturation level), and Co2 monitoring. Midazolam 0.02 
$\mathrm{mg} / \mathrm{kg}$ and fentanyl $2 \mathrm{mic} / \mathrm{kg}$ intravenous (IV) were injected as premedication. Induction of anesthesia was performed by propofol 1 or $2 \mathrm{mg} / \mathrm{kg}$ and atracurium $0.5 \mathrm{mg} / \mathrm{kg}$ IV. Maintenance of anesthesia was based on propofol 100 to 150 $\mathrm{mic} / \mathrm{kg} /$ hour and remifentanil $0.1 \mathrm{mic} / \mathrm{kg} /$ hour. According to numerical rating scale (NRS), a segmented numeric version of the visual analog scale (VAS) in which a patient chooses a number $(0-10)$ to show the intensity of pain, the postoperative pain shoulder was assessed in the patients. Nausea and vomiting were evaluated based on visualization and patients' complaint.

\section{Results}

There was no statistical difference in demographic parameters of patients between the 2 groups (Table 1 ).

Table 1. Demographic Characteristic of the Study Groups

\begin{tabular}{lccc}
\hline & $\begin{array}{c}\text { Low Pressure } \\
(\mathbf{1 0 1})\end{array}$ & $\begin{array}{c}\text { High Pressure } \\
(\mathbf{1 0 1})\end{array}$ & P Value \\
\hline Age & $44.5 \pm 7.8$ & $45.3 \pm 8.4$ & 0.24 \\
\hline $\begin{array}{l}\text { Gender } \\
\text { (male/female) }\end{array}$ & $35 / 66$ & $34 / 67$ & 0.68 \\
\hline Body mass index & $26.7 \pm 3.6$ & $26.9 \pm 4.1$ & 0.33 \\
\hline $\begin{array}{l}\text { Duration of } \\
\text { surgery, min }\end{array}$ & $32.5 \pm 8.2$ & $31.6 \pm 7.47$ & 0.25 \\
\hline
\end{tabular}

Nausea and vomiting were assessed after complete awakening of patients in recovery room and no statistical differences were observed between the 2 groups $(\mathrm{P}=0.54)$ (Table 2). Shoulder pain was evaluated during the time of patients' hospitalization and when they returned for their first visit 14 days after operation, no complaint of shoulder pain was reported; it was tried to treat shoulder pain by analgesics if NRS was more than 3. As shown in Table 2, low-pressure group showed less shoulder pain than the standard-pressure group $(\mathrm{P}=0.001)$.

Table 2. Nausea, Vomiting, and Shoulder Pain in the Study Groups

\begin{tabular}{lccc}
\hline & $\begin{array}{c}\text { Low-Pressure } \\
(\mathbf{1 0 1})\end{array}$ & $\begin{array}{c}\text { High-Pressure } \\
(\mathbf{1 0 1})\end{array}$ & P Value \\
\hline Nausea/vomiting & 18 & 19 & 0.54 \\
Shoulder pain & 57 & 86 & 0.001 \\
\hline
\end{tabular}

\section{Discussion}

The current study showed that shoulder pain significantly decreased following laparoscopic cholecystectomy by low-pressure pneumoperitoneum, than laparoscopic cholecystectomy under the standard-pressure pneumoperitoneum. In the current survey, postoperative nausea and vomiting showed no statistical difference between the 2 groups.

In some studies, shoulder tip pain was less during low-pressure laparoscopic procedures (5-7), but there was evidence that the incidence of postoperative shoulder pain was not statistically different between the low- and standard-pressure groups (8). In the current survey, shoulder pain was significantly less during low pressure laparoscopic procedures.

Nausea and vomiting are complications of laparoscopic procedures. The incidence of postoperative nausea and vomiting was assessed following low and normal pneumoperitoneum and the results were different. In some surveys there were no differences between the incidence of postop nausea and vomiting in low-and standardpressure pneumoperitoneum $(9,10)$, but some studies showed that the level of liver enzymes was controlled better during low-pressure pneumoperitoneum $(11,12)$. This finding may indirectly have a role in the prevention of postoperative nausea and vomiting. The current study showed that the incidence of nausea and vomiting was not significantly different between the 2 levels of gas pressure.

The effects of low-pressure pneumoperitoneum on different organs were evaluated. For example, the beneficial effects of low-pressure procedures on liver function were demonstrated in some studies (13-15). However, some studies showed the side effects of low-pressure and standardpressure pneumoperitoneum in laparoscopic cholecystectomy on different organs are comparable (16-18).

Finally, the beneficial effects of low-pressure laparoscopic procedures are still under evaluation and there is a need to study more about the effects of this technique in practice.

\subsection{Conclusion}

It was concluded that the incidence of postoperative shoulder tip pain following laparoscopic cholecystectomy under low-pressure pneumoperitoneum was significantly less than the procedure under the standard-pressure pneumoperitoneum. Nevertheless, more studies should be performed to assess the beneficial effects and even the hazards of low-pressure laparoscopic procedures.

\section{References}

1. Chau CH, Tang CN, Siu WT, Ha JP, Li MK. Laparoscopic cholecystectomy versus open cholecystectomy in elderly patients with acute cholecystitis: retrospective study. Hong Kong Med J. 2002;8(6):394-9. [PubMed: 12459594]. 
2. Agabiti N, Stafoggia M, Davoli M, Fusco D, Barone AP, Perucci CA. Thirty-day complications after laparoscopic or open cholecystectomy: a population-based cohort study in Italy. BMJ Open. 2013;3(2) doi:10.1136/bmjopen-2012-001943. [PubMed: 23408075].

3. Gurusamy KS, Vaughan J, Davidson BR. Low pressure versus standard pressure pneumoperitoneum in laparoscopic cholecystectomy. Cochrane Database Syst Rev. 2014;(3). CD006930. doi: 10.1002/14651858.CD006930.pub3. [PubMed: 24639018].

4. Hua J, Gong J, Yao L, Zhou B, Song Z. Low-pressure versus standardpressure pneumoperitoneum for laparoscopic cholecystectomy: a systematic review and meta-analysis. Am J Surg. 2014;208(1):143-50. doi: 10.1016/j.amjsurg.2013.09.027. [PubMed: 24503370].

5. Madsen MV, Istre O, Staehr-Rye AK, Springborg HH, Rosenberg J, Lund J, et al. Postoperative shoulder pain after laparoscopic hysterectomy with deep neuromuscular blockade and low-pressure pneumoperitoneum: A randomised controlled trial. Eur J Anaesthesiol. 2016;33(5):341-7. doi: 10.1097/EJA.0000000000000360. [PubMed: 26479510].

6. Yasir M, Mehta KS, Banday VH, Aiman A, Masood I, Iqbal B. Evaluation of post operative shoulder tip pain in low pressure versus standard pressure pneumoperitoneum during laparoscopic cholecystectomy. Surgeon. 2012;10(2):71-4. doi: 10.1016/j.surge.2011.02.003. [PubMed: 22385527].

7. Sarli L, Costi R, Sansebastiano G, Trivelli M, Roncoroni L. Prospective randomized trial of low-pressure pneumoperitoneum for reduction of shoulder-tip pain following laparoscopy. BrJ Surg. 2000;87(9):11615. doi: 10.1046/j.1365-2168.2000.01507.x. [PubMed: 10971421].

8. Sandhu T, Yamada S, Ariyakachon V, Chakrabandhu T, Chongruksut W, Ko-iam W. Low-pressure pneumoperitoneum versus standard pneumoperitoneum in laparoscopic cholecystectomy, a prospective randomized clinical trial. Surg Endosc. 2009;23(5):1044-7. doi: 10.1007/s00464-008-0119-2. [PubMed: 18810547].

9. Kim DK, Cheong ILY, Lee GY, Cho JH. Low Pressure ( $8 \mathrm{mmHg}$ ) Pneumoperitoneum does not Reduce the Incidence and Severity of Postoperative Nausea and Vomiting (PONV) following Gynecologic Laparoscopy. Korean J Anesthesiol. 2006;50(6):36-42.

10. Nasajiyan N, Javaherfourosh F, Ghomeishi A, Akhondzadeh R, Pazyar
F, Hamoonpou N. Comparison of low and standard pressure gas injection at abdominal cavity on postoperative nausea and vomiting in laparoscopic cholecystectomy. PakJ Med Sci. 2014;30(5):1083-7. doi: 10.12669/pjms.305.5010. [PubMed: 25225531].

11. Eryilmaz HB, Memis D, Sezer A, Inal MT. The effects of different insufflation pressures on liver functions assessed with LiMON on patients undergoing laparoscopic cholecystectomy. ScientificWorldjournal. 2012;2012:172575. doi: 10.1100/2012/172575. [PubMed: 22619616].

12. Lai H, Mo X, Yang Y, Xiao J, He K, Chen J, et al. Association between duration of carbon dioxide pneumoperitoneum during laparoscopic abdominal surgery and hepatic injury: a meta-analysis. PLoS One. 2014;9(8). e104067. doi: 10.1371/journal.pone.0104067. [PubMed: 25110982].

13. Hasukic S. Postoperative changes in liver function tests: randomized comparison of low- and high-pressure laparoscopic cholecystectomy. Surg Endosc. 2005;19(11):1451-5. doi: 10.1007/s00464-005-0061-5. [PubMed: 16206003].

14. Morino M, Giraudo G, Festa V. Alterations in hepatic function during laparoscopic surgery. An experimental clinical study. Surg Endosc. 1998;12(7):968-72. [PubMed: 9632872].

15. Elsageer EM, Atiya AM, Tohamy AT. Laparoscopic cholecystectomy in hepatic patients. Egypt J Surg. 2017;36(2):189-92.

16. Vijayaraghavan N, Sistla SC, Kundra P, Ananthanarayan $\mathrm{PH}$, Karthikeyan VS, Ali SM, et al. Comparison of standard-pressure and low-pressure pneumoperitoneum in laparoscopic cholecystectomy: a double blinded randomized controlled study. Surg Laparosc Endosc Percutan Tech. 2014;24(2):127-33. doi: 10.1097/SLE.0b013e3182937980. [PubMed: 24686347].

17. Koivusalo AM, Pere P, Valjus M, Scheinin T. Laparoscopic cholecystectomy with carbon dioxide pneumoperitoneum is safe even for highrisk patients. Surg Endosc. 2008;22(1):61-7. doi: 10.1007/s00464-0079300-2. [PubMed: 17943385].

18. Bogani G, Uccella S, Cromi A, Serati M, Casarin J, Pinelli C, et al. Low vs standard pneumoperitoneum pressure during laparoscopic hysterectomy: prospective randomized trial. J Minim Invasive Gynecol. 2014;21(3):466-71. doi: 10.1016/j.jmig.2013.12.091. [PubMed: 24374246]. 